\title{
The Use of Software Project Management Tools in Saudi Arabia: An Exploratory Survey
}

\author{
Nouf AlMobarak, Rawan AlAbdulrahman, Shahad AlHarbi and Wea'am AlRashed \\ Software Engineering Department \\ King Saud University \\ Riyadh, Saudi Arabia
}

\begin{abstract}
This paper reports the results of an online survey study, which was conducted to investigate the use of software project management tools in Saudi Arabia. The survey provides insights of project management in the local context of Saudi Arabia from ten different companies which participated in this study. The aim is to explore and specify the project management tools used by software project management teams and their managers, to understand the supported features that might influence their selection. Moreover, the existence of the Arabic interface, the Hijri calendar and the Arabic documentation has been specially considered, due to the nature of the local context in dealing with the Hijri calendar and the prolific use of Arabic as the formal language in communication with clients in the public sector.
\end{abstract}

Keywords-project management tools; survey; Hijri calendar; Arabic interface; software engineering; Arabic documentation.

\section{INTRODUCTION}

In recent years, the software industry has witnessed a proliferation in technology adoption within the software engineering process to deal with the increase in software complexity. In addition, the number of organizations is growing daily; which leads to many projects, tasks, risk analysis plans, scheduling and distinct resources that need to be monitored properly by the project managers. The necessitate for controlling those responsibilities accurately is to deliver a successful project; despite the fact of the impediments that the project managers or the team might face throughout the time when monitoring these simultaneously tasks (Pitch, Loch, \& Meyer, 2002) [1].

Thus, a need for project management tools has emerged in which it can help the project's leaders in administering the business and the individuals with different assigned tasks. Moreover, it provides the chance to monitor the projects' progress and its flow in the organizations that runs many tasks across the region.

The Purpose of this paper is to emphasize the features that were essential to every project managed by different project managers in different organizations with distinct sector types. As well as, highlight the use of some special features in the local context that need to be supported by the applied project management tools.

This paper is structured into five sections : section 2 which represents a concise background of the study, section 3 illustrates the methodology of the conducted survey, its participants, materials and the way it was designed . Followed that, section 4 shows the results that were collected from the survey with its analysis. Section 5 represents the discussion that was made after observing and analyzing all the participants' responses for the most utilized tools in the local context along with any demand for the Arabic language in the tool's interface or documentation. And finally, section 6 wraps up and concludes all what has been presented in this paper.

\section{BACKGROUND}

Project's with many resources, phases and due dates can be hard and stressful, however, running multiple projects with different activities, timelines and a lot of deadlines can even be harder.

The project's leader might be unable to concentrate and followup each project's detail properly.

The planning and the design of the stages of each task would be proficient and well-organized when using a software technology tools which in the end can contribute in delivering a successful project (Attarzadeh \& Ow, 2008) [2].

According to Alfaadel, Alawairdhi, and Al-Zyoud's study that aimed to investigate the most common reasons behind the success or failure of some IT projects. The results listed five reasons that lead to the project failure and one of those reasons was "poor planning and scheduling". The study was conducted in a form of a survey and was done by three hundred and eight project managers across Saudi Arabia (ALFAADEL, ALAWAIRDHI, \& ALZYO, 2012)[3].

Furthermore, (Olateju, Abdul-azeez, \& Alamutu, 2011) [4] stated in their study which was performed in Nigeria that the tools and the techniques of project management that were performed in the public institutions needs to be enhanced, due to its bad performance which causes the project's failure in many aspects.

Throughout the search that has been done on the project management tools it has been noticed that the market has presented a wide range of various tools. These tools provide a distinguished features and services that can fit with different industry's needs.

A comparative study was made by Mishra, A. and D. which presented the features of twenty popular project management tools side by side in a table to represent and compare their provided features (Mishra \& Mishra, 2013) [5]. 
To the best of our knowledge, there was an absence of studies that showed and examined the use of project management tools in Saudi Arabia. So as a result, a survey in a form of a questionnaire was distributed among many project managers in Saudi Arabia who work in different organization (private sector / governmental sector). The main goal of this survey is to provide a good overview about the tools used by project managers in the local context and what the main preference features in their opinion that should be available in the tool. Finally, to gain information about the adoption of the Arabic language and Hijiri calendar format.

\section{METHOD}

\section{A. Participants}

The participants of this study were a total of sixteen project managers all were volunteers from different organizations across Saudi Arabia. Those participants represented many companies and fields. The respondents were four females and twelve males between the ages of twentyfive and forty with the majority of them in their thirties. In addition, Arabic was their native language, and their educational level varies between bachelor and master degree.

\section{B. Materials}

A web-survey software tool called "SurveyMonkey" was chosen to conduct and prepare this study, its main purpose is to help the individuals in creating and constructing a customized online survey that fit their needs. It also provides the ability to distribute it to the intended audience to reach the maximum possible number of participants. Then lastly, gather the data and analyze it.

Moreover, the survey was passed to the participants in several ways as some was sent to their email directly, while the others received it via the social network such as Twitter and Linkedin.

The participants were given one week period to complete the survey and provide their feedback. After that, the data were gathered and were prepared to be analyzed using the analyzing service that was provided by the "SurveyMonkey" web tool. As a final step, the last result which contains numbers and percentages were revised by two team members to guarantee the correctness of the outcome.

\section{Design and procedure}

The research design of this study was non-experimental, descriptive, and review-based as it focused on a research questionnaire that tries to identify, appraise, and select different high quality project management tools and if there are any relation that might be found and linked to the ones used in the local context from the project managers' point of view and their feedback that were provided earlier in the survey .

To be able to accomplish the previous goal, an online survey was distributed to several project managers whom were considered to be our intended audience.

The survey contains ten questions (see Appendix), it was organized in three parts; the first part requires the respondent to provide the name of his organization, this will let us decide the type of the organization whether it is a private or public sector.

The second part focused on the tool's data and its features, the reason for the inclusion of this part was to gain more information about the tools that was used by the participants, such as how many tools are used during managing the different aspects of the project, the name of the tool, the features that were important when trying to select a project management tool.

The third part primarily concentrated on the existence of Arabic language and its use in the organization as the questions mentioned the Arabic documentation usage, the support for the Arabic Interface in the provided tool and to what extent it is needed, then finally, the support of the Hijiri calendar and if it was used as the main date format when determining the deadlines for each and every project phase.

The survey's answers were a closed ended question (multiple choice) in which respondents were asked to select their answer or answers out of the choice list.

In some questions, if the answer wasn't included in the list, the respondent was provided with the ability to add his answer in a comment field.

The results were collected and analyzed automatically through the "SurveyMonkey's" analyzing feature. Afterwards, a group of two team members analyzed those outcome again manually using the calculator and excel sheet to ensure the results' accuracy.

The variable in this study was the use of project management tools by different governmental agencies in Saudi Arabia and some other local organizations in different sectors, such as medical, financial, and telecommunication sectors.

Since, the participants in the survey were project managers from different organizations, the most practical way to get their feedback in a relatively short period of time, is to send them the designed survey through their direct official email as well as contacting some of them personally through phone and social media such as Twitter and Linkedin.

So, as researchers, we can assert that the participants were the exact targeted and intended audience and the survey was taken seriously by them which led to the possibility of controlling the survey environment. Hence, the exclusion of some responses was not considered in this case (Zechmeister \& Shaughnessy, 2011) [6].

The study was planned as follow, first, The project managers were contacted through the telephone, then the purpose of the study was briefly described to them at that time, they were asked about their native language, age and their level of education. After that, the respondents were requested to provide an email address to be able to send the survey's link to them.

For those who couldn't be reached by the telephone the answers for the previous questions were obtained from their personal account on the social networks (Twitter, Linkedin) where the survey's link was sent to them. 
Afterwards a request letter within the sent email declared that the response will be needed for research purpose that is related to the use of different project management tools in their local organizations that they are working in. And, that the research was intended to recognize if there is any correlation between the features founded in different used tools and the nature of the organization's business that the project manager represent. It also has been noted that the information they will offer will be kept confidential and the collected responses will be used for analytical purpose only. Finally, the participants were then thanked for their cooperation and were provided with the hyperlink of the survey.

\section{RESUlts}

The results presented below summarizes the main views and responses of different project managers. A total of 16 project managers responded to the survey, more than threequarters, $81 \%$, of participants were male project managers. These collected responses represent about $61.5 \%$ of the total project managers who were contacted.

The key information was gathered through the survey by determining the organization or governmental agency where the participated project manager stands for, so that the requirements for each and every organization can be easily understood. The Collected responses showed different organizations including, Ministry of Communication and Information Technology, local General Electric Healthcare, Zain, King Fahad Medical City, SADAD, Azian, EMC, International System Engineering, some telecommunication companies' vendors and local Nokia Siemens Networks. Responses from the governmental agency formed a small proportion of total responses about $12 \%$.

The first question outlined that more than $90 \%$ respondents use at least one project management tool to help in planning, organizing, and managing project resources and tasks. Fig 1 shows the number of project management tools used by the participated project managers.

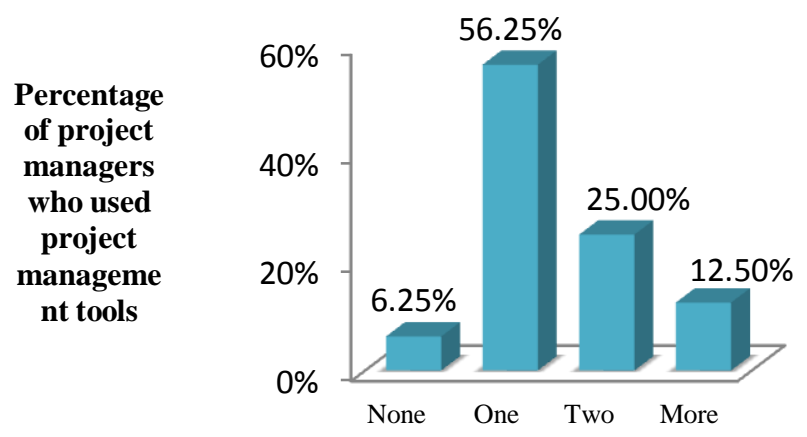

Number of Project management tools

Fig.1. The number of project management tools used by the Project Managers

The result in Fig 2 summarizes the number of project managers who used some existing softwares.
The reported responses showed that these organizations depend on other tools rather than the ones that was mentioned as the main popular project management tools used in the most global organizations in their daily tasks. Additionally, the tools listed in the survey was evaluated as the most reliable tools used by international organizations in (Garmahis, 2009) [7] and (Gorbunova, 2011)[8]. As shown in Fig 2, Microsoft Project (Microsoft, 2013) [9] had the highest rank among the used tools by the participated project managers, more than ten project managers depend on this tool in managing their projects. Other project management software tools were used, such as special templates accessed through the organization implemented portal, Microsoft Project Server (Microsoft, Project Server 2013, 2013) [10] and Excel spreadsheets.

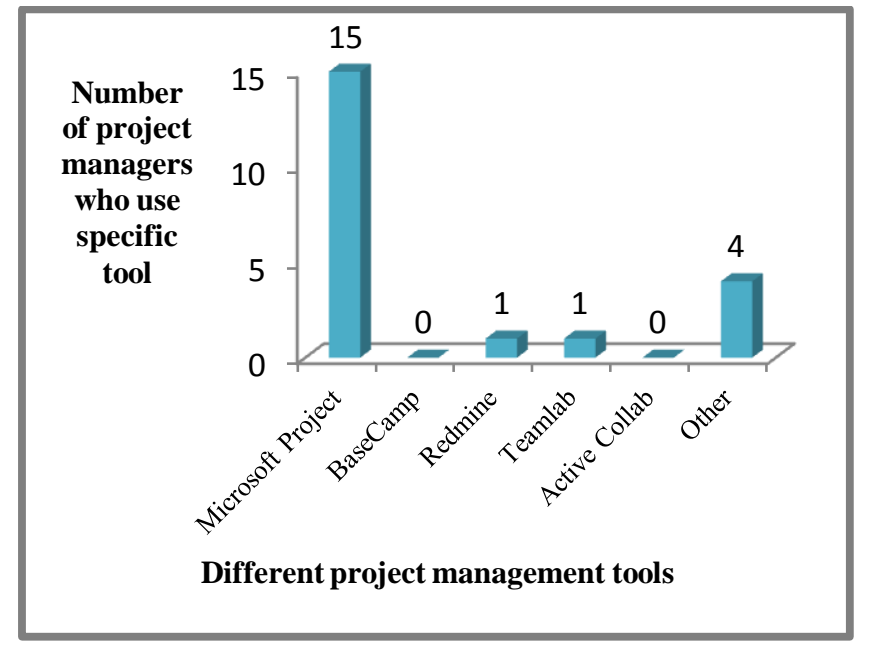

Fig.2. Project management tools used by different project managers in Saudi Arabia

Respondents were asked about their opinion on the most features that influenced their selection of any project management tool. To simplify this question and to limit our results; a list of some project management tool's features were picked and listed (Schwalbe, 2012) [11] as shown in the survey at Appendix A.

Most Project managers, 10 out of 16 were looking for the simplicity in choosing a specific tool, where the second most feature that was looked for was the ability to integrate the used project management tool with other unlike tools to combine project planning functions with added operational functions that does not exist in the integrated software tool, such as collaboration, document version control, and issue tracking activities (Duggan) [12].

While the third most important features evaluated equally by the participated project managers were time and resource estimations and tracking project progress. Moreover, less than half project managers, 6 out of 16 , founded that estimating the cost feature considered as a significant feature to look for before selecting a tool. Some other features were selected by at most 5 project managers as important features, shown in Fig 3. 


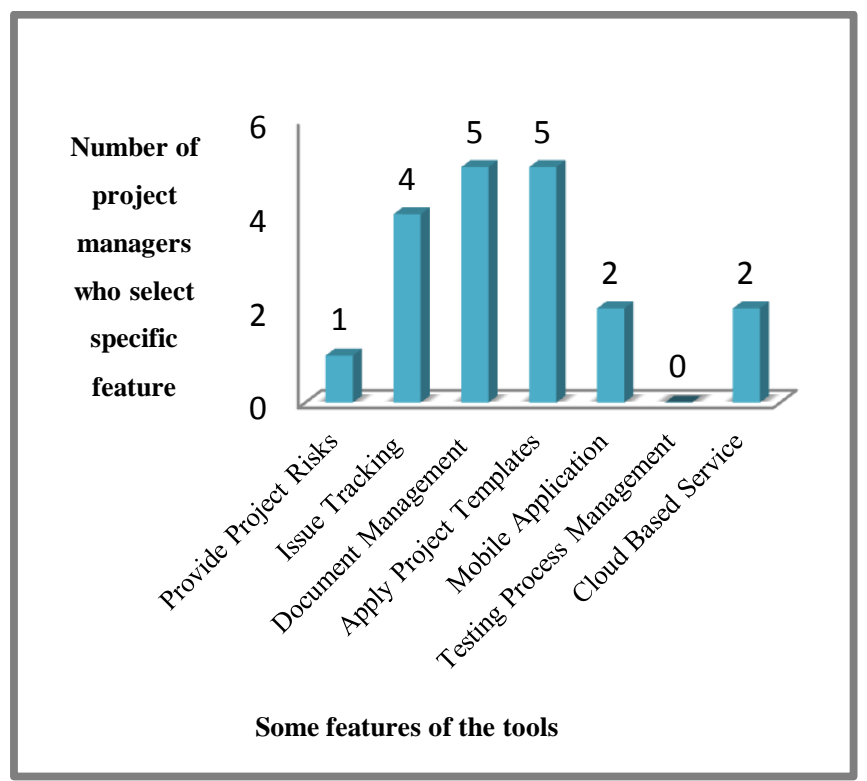

Fig.3. A sample of the tool's features selected by the Project Managers

A small percentage $18.75 \%$ of the used tools supported Arabic interface, which was unexpected in an Arabic environment. In addition, more than $80 \%$ stated that the Arabic interface wasn't supported or that they don't even know about its availability in their tool. In case of supporting this feature, the participants were asked if they were using this feature in their daily work. $100 \%$ of the project managers reported that they don't look for this kind of support for managing their daily project tasks as they didn't need to use the Arabic interface, even thought, it was supported by the used tool.

The participants have also been asked about the support of the Hijiri calendar. The results showed that the Hijiri calendar was supported by $37.50 \%$ of the tools that have been reported previously, whereas, $25 \%$ said that it wasn't supported. Moreover, $18.75 \%$ indicated that they don't need to use the Hijri calendar in their projects. At the same time, $18.75 \%$ responded that they don't know whether the tool support such feature or not. Fig 4 shows the project managers' responses about the support for a Hijiri calendar in their tool.

Furthermore, The project managers were asked if they need to use the Hijiri calendar in their project's due dates and deadlines in the case if this feature was supported. About $22 \%$ of the project managers do use the Hijiri calendar in their business while 78\% don't, as shown in Fig 5.

As for the support of the Arabic documentation, 25\% of the project managers reported that their tool provides the support for the Arabic documentation. While, 25\% said that the Arabic documentation wasn't supported by the tool they use. Table 1 illustrates the support of the Arabic report.

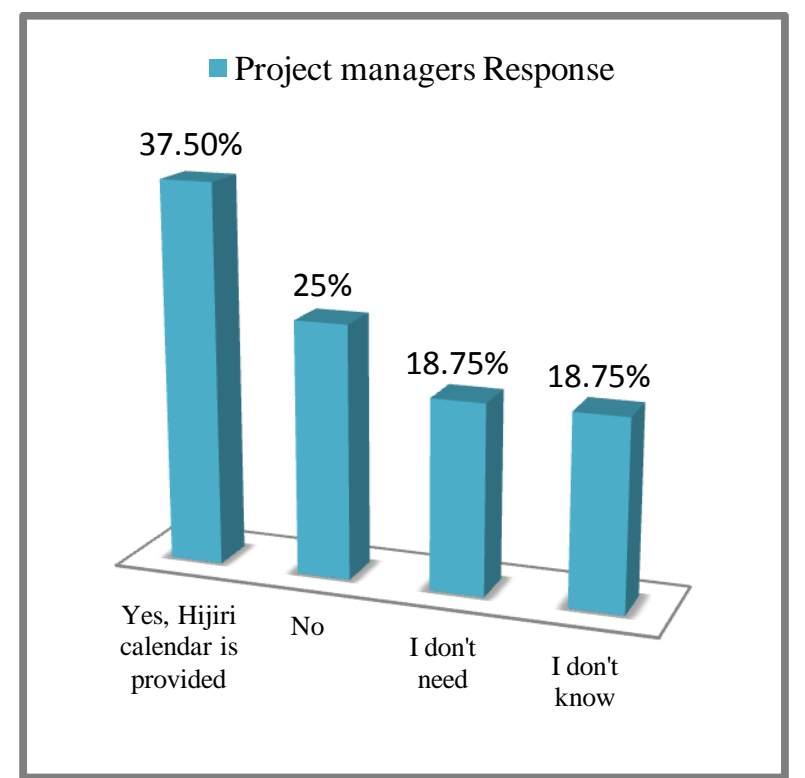

Fig.4. Support for Hijiri calendar in the tools used by the project managers.

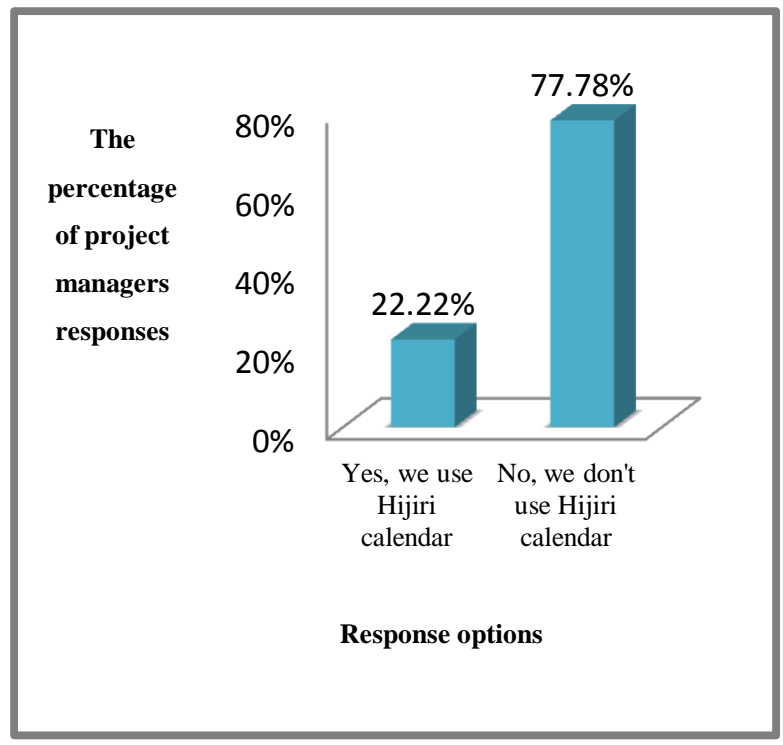

Fig.5. Use of the Hijiri calendar format in the organization's projects.

$31.25 \%$ of the respondents didn't need the Arabic documentation in their organization and only $18.75 \%$ indicated that they don't know whether their tool support the Arabic report. If a need for an Arabic report has arisen and If the used tool doesn't support the Arabic documentation, participants were asked about the actions that need to be performed to overcome this issue. Twelve project managers have answered this question, eight said that they use manual translation whereas, one indicated that they used a translation tool while, the rest specified that they don't need Arabic documentation in their work. 
TABLE I. SUPPORT FOR THE ARABIC DOCUMENTATION

\begin{tabular}{|c|c|c|}
\hline \multirow{2}{*}{ Response options } & \multicolumn{2}{|c|}{$\begin{array}{l}\text { Project management tools that } \\
\text { support Arabic Documentation }\end{array}$} \\
\hline & Number of respondents & Percentage \\
\hline $\begin{array}{l}\text { Yes, the tool support } \\
\text { Arabic documentation }\end{array}$ & 4 & $25 \%$ \\
\hline $\begin{array}{l}\text { No, the tool doesn't } \\
\text { support Arabic } \\
\text { documentation }\end{array}$ & 4 & $25 \%$ \\
\hline I don't need & 5 & $31.25 \%$ \\
\hline I don't know & 3 & $18.75 \%$ \\
\hline
\end{tabular}

\section{DISCUSSION}

Since the official language in Saudi Arabia is Arabic, it was expected to be used as the main written and spoken communication language in different private and governmental organizations.

However, according to our study, the results showed that despite having Arabic as the official language in the context of the study, project managers perceived that Arabic support of project management tools is not essential because software engineering phases and tasks are mainly conducted in English. Therefore, not supporting the Arabic Interface doesn't affect the manager's and/or the organization's decision when selecting a tool. Moreover, the Hijiri calendar wasn't the used format by most of the project managers in tracking the project's timeline.

Although, the official followed calendar format in the local context is Hijiri calendar. From the observations, it is noted that the official communication for projects is often conducted in Arabic; specifically with government and industry projects. It seems that the external documentation is often adapted from the internal documentation used by project managers in the local contexts. This highlights an opportunity for project management software tools to address this gap in supporting software engineering projects, particularly in the local context where documentation can be effectively generated and communicated in the format appropriate to all stakeholders and individuals involved.

During distributing the survey to gain the needed information from the largest possible audience, we have noticed that we gain a high response from managers which have been contacted in person. On the other hand, the response rate was lower for project managers who were contacted through the social network as twitter.

\section{CONCLUSION}

A survey study was undertaken as part of looking for a dependency by some local organizations in different sectors and governmental agencies, on some of project management tools in administrating, managing and tracking several project phases.

The main purpose of the distributed survey was to find out, in case of using project management tools by the organizations, the key element and the players that lead to choose and use a precise project management tool. Also, to find and discover if there were any special requirements that need to be implemented in the tools that are used by the participant of an organization to cope with the local business needs.

We can conclude that, when analyzing the results it was found that the most dominant software tool used by project managers in Saudi Arabia was Microsoft project and a slight portion used Microsoft Excel Sheets to keep track of their everyday tasks. Additionally, the three top features that the project manager looks for in any tool were, in order, "Simplicity" then "Ability to integrate with other tools, as well as, provide time estimation feature" and "project progress \& changes" along with "project resource estimation feature" which was rated evenly.

Moreover, The Arabic interface and the Arabic documentation weren't essential in the industry where the participants' work.

Finally, regardless of the fact that the Hijri calendar is the calendar format that is officially used in Saudi, the survey's result revealed the fact that it wasn't popular as it was expected to be and instead Georgian calendar format was followed.

\section{ACKNOWLEDGMENT}

This research paper would not have been possible without the interaction of many project managers, who consider the time to provide their responses in a relatively timely manner without any compensation. We would like also to extend our thanks and acknowledgment to Dr. Areej Alwabil for her dedicated effort in sharing with us her experience in project management, providing us with all the needed concepts, and allocating the time to guide us in writing this paper.

\section{REFERENCES}

[1] Pich, M. T., Loch, C. H., and De Meyer, A. (2002). " On uncertainty, ambiguity, and complexity in project management. Management Science ", vol. 48(8), pp.1008-1023.

[2] Attarzadeh, I., Ow, S. (2008). " Project Management Practices: The Criteria for Success or Failure ". Communications of the IBIMA, vol. 1, pp.234-241.

[3] Alfaadel, F., Alawairdhi, M., and Al-Zyoud, M. (2012, April). " Success and failure of IT projects: a study in Saudi Arabia ". In Proceedings of the 11th WSEAS international conference on Applied Computer and Applied Computational Science, pp.77-82.

[4] Olateju, O. I., Abdul-azeez, I. A., and Alamutu, S. A. (2011). " Project Management Practice In Nigerian Public Sector-An Empirical Study ". Australian Journal of Business and Management Research, vol. 1(8), pp. 01-07.

[5] Mishra, A. and Mishra, D., (2013). " Software project management tool : a brief comparative view ". ACM SIGSOFT Software Engineering Notes, vol. 38 (3), pp.01-04.

[6] Zechmeister,E. and Shaughnessy, J., (2011). " Research Methods in Psychology ". US: McGraw-Hill College, pp.161-175. 
[7] Michael Garmahis. (2009). " Top 20 Project Management tools" . Available: http://garmahis.com/reviews/top-project-managementtools/. Last accessed 10th June 2013.

[8] Nina Gorbunova. (2011). " 10 Most Popular Online Project Management Solutions ". Available: http://www.famousbloggers.net/most-popularonline-project-management-solutions.html. Last accessed 10th June 2013.

[9] Microsoft. (2013). Microsoft Project. Available: http://office.microsoft.com/en-us/project/enterprise-project-portfoliomanagement-in-the-cloud-project-online-FX103802026.aspx. Last accessed 10th June 2013.

[10] Microsoft. (2013). Project Server 2013. Available: http://office.microsoft.com/en-us/project/project-portfolio-managementfor-the-enterprise-project-server-FX103802061.aspx. Last accessed 10th June 2013.

[11] Schwalbe, K. (2012). "An Introduction to Project Management". US: Schwalbe publishing, pp.11-30.

[12] Duggan, T. , " The Importance of Integrated Project Management Tools ". Available: http://www.ehow.com/info_8384297_importanceintegrated-project-management-tools.html\#ixzz2Us8hZB55. Last accessed 10th June 2013.

\section{APPENDIX}

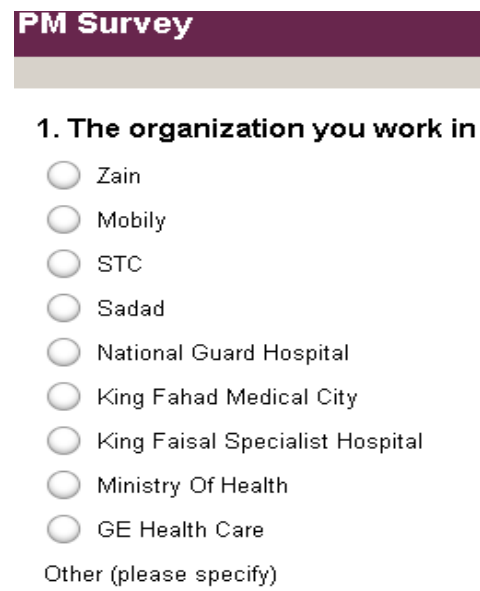

2. How many Project Management tools do you use ?

None
One
Two
more
(please specify)

\section{What are the tools that you use?}

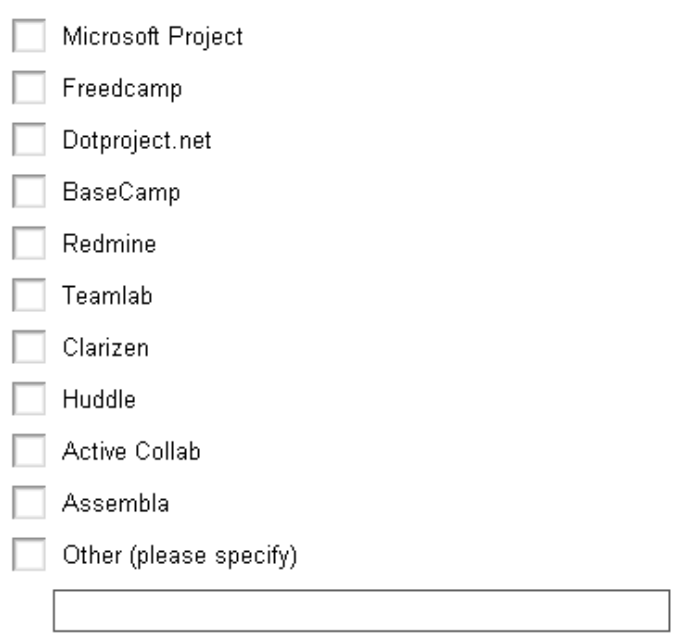

\section{Which of the following MOST influenced your choice in Question 2 ?}

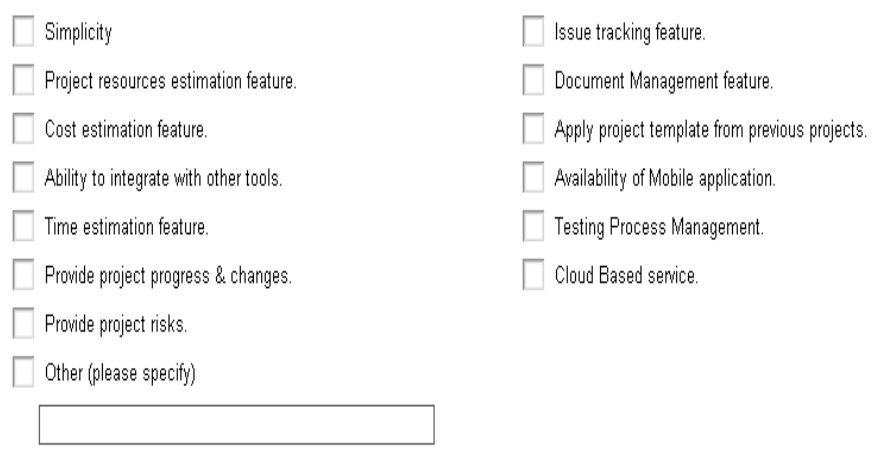

5. Does your tool support Arabic Interface?

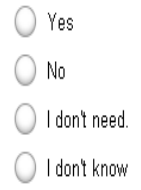

6. If Yes, Do you use Arabic interface?

Yes

No 


\section{Does it support Hijiri calendar?}

Yes

No

I don't need

I don't know

8. If yes, do you use the Hijri calendar in your projects?

Yes

No

9. Does your tool support Arabic documentation?
Yes
No
I don't need
I don't know

\section{If No, What do you do in case you need Arabic reports?}

- Manually translation

- Using a translation tool.

Other (please specify) 